\title{
O efeito de diferentes métodos de ensino de inglês como língua estrangeira na compreensão de textos em inglês
}

\author{
Ana Almeida Falcão \\ Alina Galvão Spinillo \\ UFPE
}

O estudo examinou a influência de diferentes métodos de ensino de inglês como língua estrangeira na compreensão de textos em inglês. Trinta alunos de inglês falantes nativos do português (12 a 14 anos) foram investigados. Metade da amostra freqüentava cursos de inglês que adotavam uma Abordagem Comunicativa, e a outra metade freqüentava cursos que adotavam uma Abordagem Áudiolingual. A compreensão de textos, em inglês e em português, foi avaliada através da reprodução de um texto lido e perguntas sobre o texto. Apesar de todos os participantes apresentarem níveis semelhantes de compreensão de textos em português, quando compreendiam o texto em inglês, os alunos da Abordagem Comunicativa mostraram níveis mais elaborados de compreensão do que os alunos da Abordagem Audiolingual. Concluiu-se que o método de ensino desempenha papel importante na compreensão de textos em inglês.

This study examines whether different methods of teaching a foreign language would have an effect on text comprehension in that language. The participants were thirty students, Portuguese native speakers, aged 12-14. Half of them attended schools that adopted the Communicative Approach and the other half attended schools that adopted the Audiolingual Approach. Text comprehension abilities, in Portuguese and in English, were evaluated in two tasks: reproduction of a text and questions about a text. Although all the students showed similar levels of comprehension when reading Portuguese texts, when it came to understanding English texts, the students in the Audiolingual Approach program showed more elementary levels of comprehension than those in the Communicative Approach program. 
De caráter interdisciplinar por excelência, o estudo da compreensão de texto permeia todas as áreas do conhecimento, sendo considerado um dos mais intrincados processos da mente humana. De natureza lingüística e cognitiva, a compreensão de textos tem sido tema de estudo de psicólogos, lingüistas e educadores.

Muitos estudiosos na área concentram-se na criação de modelos de compreensão de textos que descrevem os fatores cognitivos e linguí́sticos envolvidos no processo de compreensão (e.g., Graesser $e$ Briton, 1996; Graesser, Swammer, Bagett e Sell, 1996; Graesser e Zwaam, 1995). Diversos modelos são encontrados na literatura, sendo o modelo de Construção-Integração (CI) proposto por Kintsch (Kintsch, 1988; 1998; Kintsch e van Dijk, 1978; van Dijk e Kintsch, 1983) o mais abrangente e de maior expressão na área. O modelo focaliza tanto o conhecimento de mundo do receptor do texto como os elementos textuais, especificando duas fases durante o processo de compreensão: (a) construção - na qual um modelo mental é construído pelo leitor a partir de seus objetivos, conhecimento de mundo e das informações veiculadas no texto. Nesta fase, são estabelecidas conexões entre as proposições, são ativados determinados conhecimentos anteriores e inferências são estabelecidas; (b) integração - processo de natureza local e geral que ocorre sempre que uma informação nova é adicionada, permitindo a construção de uma rede integrada de sentidos. Este processo envolve a identificação de inconsistências a nível local (entre proposições e passagens do texto) e a nível geral (em relação ao texto como um todo). A integração que ocorre no final do processo tem um caráter especial, pois reflete a compreensão do tex to como um todo organizado e coerente.

Os estudos empíricos conduzidos por inúmeros autores (e.g., Perfetti, Marron e Foltz, 1996; Oakhill e Yuill, 1996) apontam uma série de fatores como responsáveis pela compreensão: (a) fatores lingüisticos: sintáticos, semânticos, léxicos, habilidade de decodificação; (b) fatores cognitivos: memória de trabalho, capacidade de monitoramento, e de integração das informações veiculadas no texto e a capacidade de estabelecer inferências.

Dentre os fatores linguísticos, a habilidade de decodificar palavras é considerada importante, visto que limites na decodificação durante a leitura são responsáveis por muitas das dificuldades de compreensão. Entretanto, a decodificação não é suficiente para explicar as dificuldades no processo de compreensão, pois leitores sem dificuldades de 
decodificação não são, necessariamente, bons compreendedores (Yuill e Oakhill, 1991).

Dentre os fatores cognitivos, a memória de trabalho e as inferências têm sido amplamente investigadas. Em extensa obra dedicada à compreensão de leitura, Yuill e Oakhill (1991) e Oakhill e Yuill (1996) afirmam que longe de ser um simples processo de busca de informações textuais explícitas, a compreensão é um processo de integração e construção de significados. Muitos dos estudos conduzidos pelas pesquisadoras enfatizam a necessidade de diferenciar as informações literais das informações inferenciais construídas durante a compreensão. As informações literais seriam aquelas explicitamente encontradas na superfície do texto; enquanto as inferenciais seriam informações implícitas, derivadas da interação entre o conhecimento de mundo do leitor e o texto em si.

As inferências, portanto, assumem papel crucial na compreensão de textos, como enfatizado, por Graesser, Singer e Trabasso (1994) que consideram que a compreensão de textos é determinada pelo estabelecimento de inferências construídas a partir do conhecimento de mundo e das informações veiculadas no texto.

Segundo Marcuschi (1996), a compreensão de textos é uma atividade de co-autoria realizada pelo autor e pelo leitor do texto, de forma que o texto é parcialmente produzido pelo autor, e completado pelo leitor. Nesta perspectiva, como também na perspectiva dos autores acima citados, o processo inferencial tem papel de destaque, em que a compreensão depende de conhecimentos pessoais prévios (informações não textuais) e de informações textuais que, de maneira integrada, permitem a construção de sentidos. Entretanto, ao mesmo tempo em que a compreensão de textos envolve uma certa liberdade por parte do leitor, esta liberdade é, ao mesmo tempo, direcionada pelo próprio texto, de modo a evitar leituras incorretas ou não autorizadas. É a partir das inferências, portanto, que se estabelecem relações entre as informações textuais e entre essas e o conhecimento de mundo do leitor.

As inferências e a capacidade de integrar informações no texto foram detalhadamente examinadas por Yuill e Oakhill (1991). Em um dos estudos conduzidos pelas autoras, crianças de 7-8 anos com níveis distintos de compreensão de textos (elementar e elaborado) ouviam, individualmente, a leitura de oito pequenas histórias. Após a apresentação de cada texto, o examinador lia quatro sentenças, tendo a criança que 
identificar se a sentença lida estava ou não presente na história que acabara de ouvir. As sentenças eram de três tipos: (a) sentenças originais que estavam presentes no texto (sentenças literais); (b) sentenças que não estavam presentes no texto original, mas que continham informaçōes que podiam ser inferidas a partir dele (sentenças inferenciais válidas); e (c) sentenças que não estavam presentes no tex to original e que continham informações que não podiam ser inferidas a partir dele (sentenças inferenciais inválidas). Verificou-se que as crianças com um bom nível de compreensão aceitavam tanto as sentenças literais como as sentenças inferenciais válidas como estando presentes no texto original; enquanto as crianças com dificuldades de compreensão aceitavam apenas as sentenças literais como estando presentes no texto original. Concluiu-se que as crianças com um bom nível de compreensão eram capazes de integrar diferentes passagens do texto, de estabelecer inferências e de representar o texto como um todo (modelo mental). As crianças com dificuldades, por outro lado, apresentavam uma memória de trabalho capaz de levá-las a reconhecer as sentenças literais como estando presentes no texto original, porém, não construíam ativamente uma rede integrada de sentidos que permitisse estabelecer inferências válidas.

Em um segundo estudo, Yuill e Oakhill (1991) investigaram as relações entre a habilidade de fazer inferências e a memória de trabalho. Utilizando os mesmos dois grupos de crianças, pediu-se aos participantes que lessem, em voz alta, quatro histórias e respondessem perguntas literais e inferenciais sobre cada uma. Duas condições foram aplicadas: metade dos participantes em cada grupo respondia as perguntas sem que o texto estivesse disponível, e a outra metade respondia as perguntas com o texto presente, disponível para consulta. O principal resultado foi que as crianças com um bom nível de compreensão apresentaram melhor desempenho que aquelas com dificuldades de compreensão nas perguntas inferenciais na condição sem texto, pois eram capazes de construir sentidos a partir das informações implícitas no texto, quer o texto estivesse presente ou não. As crianças com dificuldades, por sua vez, apresentavan dificuldades em estabelecer inferências tanto na condição sem texto como na condição com texto. Segundo as autoras, é provável que essas crianças não percebam que podem e devem usar o conhecimento de mundo que possuem, ao tentar compreender um texto, faltando-lhes desenvolver habilidades metacognitivas como o monitoramento e a consciência lingüística. 
Os resultados deste estudo mostram que a memória de trabalho, embora relevante, não pode ser considerada fator determinante da compreensão, pois mesmo quando o texto encontrava-se disponível para consulta, dispensando o uso da memória de trabalho durante a compreensão, as crianças com dificuldades de compreensão eram limitadas quanto ao estabelecimento de inferências, limite este que não decorria de um déficit na memória de trabalho, mas de dificuldades de processamento e, mesmo, de discernimento sobre a utilidade dos conhecimentos de mundo e de estratégias metacognitivas que auxiliam na compreensão de texto.

O estudos até então relatados, foram conduzidos com crianças em sua língua materna, sendo importante discutir os resultados de pesquisas que examinam a compreensão de textos em uma língua diferente da língua materna (língua estrangeira e segunda língua).

\section{Pesquisas sobre compreensão de textos em língua estrangeira e em uma segunda língua}

Upton (1997) examinou o papel desempenhado pela língua materna e pela segunda língua nas estratégias de compreensão de textos escritos na segunda língua, investigando, ainda, se haveria diferenças no uso dessas estratégias em função do nível de proficiência do leitor na segunda língua. Para tal, estudantes universitários japoneses alunos de inglês como segunda língua foram divididos em dois grupos que varjavam quanto ao nivel de proficiência em inglês. A tarefa consistia em ler um texto em voz alta e ao mesmo tempo explicitar como faziam para superar as dificuldades que encontravam para compreender o texto em inglês, sendo a leitura e os comentários de cada participante gravados em protocolos. Em seguida, através de uma entrevista retrospectiva, os participantes eram solicitados a ouvir seus próprios protocolos e a responder perguntas que objetivavam esclarecer e explicar os comentários e verbalizações feitas durante a leitura. Os resultados mostraram que os alunos em níveis de proficiência mais elementar tendiam a usar a língua materna, recorrendo à tradução de palavras e sentenças, e recorrendo à paráfrase. A língua materna também era freqüentemente usada como a língua para pensar sobre o significado do texto. Já os alunos com nível mais elevado de proficiência descreviam partes do processo de compreensão em inglês, 
utilizando estratégias mais globais para a interpretação do texto, e, ainda, descreviam seus pensamentos na segunda língua. Assim, a língua que os leitores usam para pensar e para processar um texto em uma segunda língua corresponde ao nível de proficiência que possuem. Os menos proficientes dependem em grande parte da língua materna para determinar o significado de palavras e do texto como um todo e também para checar sua compreensão. Os leitores mais proficientes, por outro lado, são menos dependentes da língua materna ao implementarem estratégias de compreensão. Concluiu-se que quanto mais proficientes na segunda língua, menos frequientemente recorrem à língua materna durante o processo de compreensão e durante a explicitação das estratégias de compreensão.

Pinto (1996) realizou um estudo com oito alunos de pós-graduação brasileiros (falantes nativos do português) que participavam de um curso de inglês como língua estrangeira. No início do curso os participantes foram avaliados em compreensão de textos através de entrevistas, questionários e observações em sala de aula. As dificuldades de compreensão inicialmente identificadas foram superadas após uma intervenção voltada para promover o controle dos processos cognitivos relevantes para a compreensão (dedução, inferência e a integração de idéias). A intervenção se caracterizava por um programa instrucional destinado a levar os alunos a refletir sobre a natureza do processo de lejtura de textos em inglês; a monitorar a compreensão de textos e a desenvolver estratégias para superar suas dificuldades durante a leitura. Após a intervenção observou-se ganhos linguísticos e mudanças no estilo de leitura dos alunos os quais passaram a usar estratégias cognitivas voltadas para o estabelecimento de inferências e para o monitoramento da compreensão. Ao mesmo tempo, os alunos tornaram-se mais independentes e com atitudes mais favoráveis à aprendizagem de uma língua estrangeira. A importância deste e de outros estudos de intervenção reside em ensinar o aluno a aprender melhor, enfatizando não somente a língua a ser aprendida, mas, sobretudo, a melhor forma de aprendê-la.

Apesar de raras, algumas pesquisas comparam a eficácia de diferentes métodos de ensino quanto a habilidades específicas como ler, escrever, compreender e falar. Um exemplo, é o estudo de Campbell (1989) que investigou o efeito de diferentes métodos de ensino sobre a aprendizagem do Espanhol como língua estrangeira por falantes nativos de inglês. $O$ objetivo do estudo era testar a eficácia de um método 
particular de ensino denominado Guided Design no desenvolvimento de habilidades cognitivas de alto nível: proficiência em leitura e escrita do Espanhol. Universitários alunos de curso de espanhol foram divididos em três grupos, em função do método de ensino aplicado. Um grupo de alunos foi submetido ao método Guided Design, programa baseado em um modelo de aprendizagem que envolve uma progressão sistemática em uma série de atividades voltadas para estimular habilidades intelectuais de alto nível através de situações de resolução de problemas que estimulavam o pensamento crítico. Um segundo grupo foi submetido a uma versão simplificada do Guided Design a qual envolvia apenas parte do programa. A um terceiro grupo foi aplicado o Cognitive-Code, método de ensino que enfatizava o estudo das estruturas gramaticais através de exercícios de gramática, explicações fornecidas pelo instrutor e pelo livro de inglês adotado. Os resultados indicaram que os alunos submetidos ao programa Guided Design apresentavam um maior domínio da escrita do que os alunos dos dois outros grupos; e que os alunos submetidos à versão simplificada do Guided Design apresentavam resultados em escrita superiores aos alunos do Cognitive-Code. A habilidade de compreensão, entretanto, não diferia entre os três grupos. Segundo a autora, este resultado decorreu do fato de que o material didático utilizado nos três grupos não fornecia leituras frequientes em espanhol, havendo lacuna na exposição de leituras em espanhol.

Considerando-se os estudos citados, nota-se que de um lado estão pesquisas que examinam a compreensão de textos (Pinto, 1996; Upton, 1997) e de outro aquelas que examinam a eficácia de diferentes métodos de ensino (Campbell, 1989). Entretanto, por ser a compreensão de textos habilidade extremamente relevante na aprendizagem de uma nova língua, torna-se importante examinar, através de estudo especificamente voltado para este fim, se a habilidade de compreensão de textos seria influenciada por diferentes métodos de ensino de língua estrangeira, sendo este o objetivo da presente investigação.

Antes, porém, da apresentação do estudo e seus resultados, tornase necessário caracterizar brevemente os dois métodos de ensino de inglês como língua estrangeira que serão abordados nesta investigação: Método Audiolingual e a Abordagem Comunicativa. 


\section{Método Audiolingual e a Abordagem Comunicativa}

Segundo Cohen (1998), aprender uma segunda língua significa aprender a língua na comunidade de falantes desta língua; enquanto que aprender uma língua estrangeira significa aprender uma dada língua em uma comunidade na qual a língua falada difere daquela que está sendo aprendida. Desta forma, aprender inglês no Brasil, cuja língua materna é o português, significa aprender inglês como língua estrangeira.

Apesar de variações entre eles, os cursos de inglês tendem a adotar, basicamente, duas perspectivas distintas de ensino: uma em que a aprendizagem se baseia fundamentalmente na tradução, memorização e exercícios de fixação; e outra em que aprender significa se comunicar adequadamente em diversos contextos sociais. Essas duas perspectivas se traduzem na prática em dois métodos distintos: um método centrado na língua enquanto código, representado pelo Método Audiolingual (Audio-Lingual Method) ${ }^{8}$, e outro, centrado na língua enquanto comunicação, representado pela Abordagem Comunicativa (Communicative Approach) $)^{9}$. Inúmeros autores procuraram caracterizar cada uma dessas abordagens (e.g.; Canale e Swain, 1980; Littlewood, 1981; 1984; Richards e Rodgers, 1986).

A teoria de língua subjacente ao Método Audiolingual derivou da visão proposta por linguiistas americanos na década de 50 , conhecida por lingüística estrutural, desenvolvida em oposição à gramática tradicional. Nela, a língua é considerada como um sistema de elementos relacionados estruturalmente para codificação do significado. Aprender uma língua consiste em dominar os elementos ou blocos construtivos de língua e aprender as regras através das quais os elementos são combinados.

A teoria de língua subjacente à Abordagem Comunicativa enfatiza a língua como comunicação, de forma que os aprendizes precisam dar conta não somente das formas lingüísticas, significados e funções, mas, também, de como a língua é estruturada em cada contexto social em função dos papéis desempenhados pelos interlocutores. O ensino tem

\footnotetext{
"Também denominado Abordagem Estrutural (Structural Approach).

A Abordagem Comunicativa é também denominada Ensino Comunicativo da Língua (Communicative Language Teaching) e Abordagem Funcional (Functional Approach).
} 
por objetivo desenvolver no falante uma competência comunicativa, tornando-o capaz de adquirir conhecimentos e habilidades para usar a língua em diversas situações. Esta abordagem considera que a língua: (a) é um sistema para expressão de significados; (b) tem por função básica a interação e a comunicação; e (c) possui uma estrutura que reflete seus usos e funções.

Tais diferenças quanto ao conceito de língua adotado por essas duas abordagens se traduzem na prática em características metodológicas distintas, como sugerem Finocchiaro e Brumfit (1983, pp.91-93); características estas sumariadas na Tabela 1.

\begin{tabular}{|c|c|}
\hline M étodo Aucliolingual & Abordagem Comrunicativa \\
\hline $\begin{array}{l}\text { Enfase na estrutura mais do que } \\
\text { no sigrificado }\end{array}$ & $\begin{array}{l}\text { Significado é central, berr como a } \\
\text { funçáo }\end{array}$ \\
\hline $\begin{array}{l}\text { Memorização de diálogos } \\
\text { baseados na estrutura }\end{array}$ & $\begin{array}{l}\text { Diálogos centrados em funções } \\
\text { comuricativas, pouca memorização }\end{array}$ \\
\hline $\begin{array}{l}\text { Língua näo é, necessariamente, } \\
\text { contextualizada }\end{array}$ & $\begin{array}{l}\text { Contextualização é a premissa } \\
\text { básica }\end{array}$ \\
\hline $\begin{array}{l}\text { Aprender a lingua é aprender } \\
\text { estruturas, sons ou palavras }\end{array}$ & $\begin{array}{l}\text { A prender a lingua é aprender a } \\
\text { comuricar-se }\end{array}$ \\
\hline Treino é estimulado & $\begin{array}{l}\text { Comunicaçāo eficiente é } \\
\text { estimulada }\end{array}$ \\
\hline Repetição é uma técrica central & $\begin{array}{l}\text { Repetição ocorre, mes não é } \\
\text { essencial }\end{array}$ \\
\hline $\begin{array}{l}\text { Busca-se uma prontincia de } \\
\text { falante nativo }\end{array}$ & $\begin{array}{l}\text { Busca-se uma pronúncia } \\
\text { compreensivel }\end{array}$ \\
\hline $\begin{array}{l}\text { Atividades comunicativas são } \\
\text { incentivadas aperas após longo } \\
\text { período de exercicios de } \\
\text { repetição }\end{array}$ & $\begin{array}{l}\text { Atividades comunicativas säo } \\
\text { estimuladas deste o início }\end{array}$ \\
\hline $\begin{array}{l}\text { O uso da língua materna é } \\
\text { desaconselhado }\end{array}$ & $\begin{array}{l}\text { Aceita se o lso da lingua materna, } \\
\text { quando necescario }\end{array}$ \\
\hline $\begin{array}{l}\text { Ler e escrever säo aguardados } \\
\text { até que o aluno consiga falar }\end{array}$ & $\begin{array}{l}\text { Ler e escrever são incentivados } \\
\text { desde o inicio }\end{array}$ \\
\hline Competência lingüística & Competência comunicativa \\
\hline $\begin{array}{l}\text { A seqüencia de unidades é } \\
\text { determinada pelos princípios de } \\
\text { complexidade lingüistica }\end{array}$ & $\begin{array}{l}\text { A seqüência de unidades é } \\
\text { determinada por consideraçóes } \\
\text { sobre o conteido, a função e o } \\
\text { significado }\end{array}$ \\
\hline $\begin{array}{l}\text { 'Lingura é hábito' e os erros } \\
\text { devern ser evitados }\end{array}$ & $\begin{array}{l}\text { Lingua é criada pelo individuo, } \\
\text { geralmente através de tentativa e } \\
\text { erro }\end{array}$ \\
\hline
\end{tabular}

Tabela 1: Resumo das principais características dos dois métodos de ensino 
Uma vez que o presente estudo coloca em perspectiva esses dois métodos de ensino, torna-se relevante apresentar, pelo menos em linhas gerais, como a compreensão de textos é trabalhada em sala de aula, segundo cada um desses métodos. Para tal, foram realizadas observações em salas de aula, análise do material didático adotado nas atividades que envolviam compreensão de textos e entrevistas informais com os professores.

No Método Audiolingual, o ensino das habilidades orais (ouvir e falar) antecede o ensino das habilidades escritas de ler e de escrever. Como o principal objetivo é automatizar as respostas orais do aprendiz, os textos trabalhados em sala de aula constituem-se, prioritariamente, em diálogos entre interlocutores em situações diversas, enfatizando-se a pronúncia correta, a entonação e o ritmo de leitura do texto escrito. O texto é tratado como um instrumento de treino de leitura (decodificação de palavras, aspectos estruturais da língua e ampliação de vocabulário) mais do que como um instrumento que veicula um sentido a ser compreendido. Observa-se uma ênfase na decodificação de informações literais, isto é, naquelas que estão explicitamente mencionadas no texto.

$\mathrm{Na}$ Abordagem Comunicativa, o trabalho com as quatro habilidades - ouvir, falar, ler e escrever - é integrado. Há uma grande variedade de tipos de textos veiculados em sala de aula, mesmo nas fases iniciais do curso, tais como: cartas, mensagens, anúncios de jornal, diálogos, pequenos relatos, histórias e textos descritivos. Figuras e ilustrações servem de suporte à compreensão. Aos aprendizes é solicitado que identifiquem os diferentes tipos de textos apresentados, estabelecendo relações entre o conhecimento de textos em sua própria língua e os tipos de textos na língua estrangeira. O texto é tratado, prioritariamente, como um instrumento que veicula um sentido a ser compreendido, estando este sentido associado a informações veiculadas no texto e ao conhecimento de mundo do leitor.

Diante dessas diferenças conceituais e metodológicas, é importante perguntar: Seriam tais diferenças capazes de gerar diferentes níveis de compreensão de textos nos alunos? Esta é a questão principal tratada no estudo descrito a seguir. 


\section{Método}

\section{Participantes}

Trinta alunos, de ambos os sexos, falantes do português como língua materna, com idades entre 12 e 14 anos, de classe média, freqüentando escolas de inglês como língua estrangeira na cidade do Recife. Metade dos participantes eram alunos de escola cuja prática de ensino consistia na Abordagem Comunicativa e a outra metade era alunos de escola cuja prática de ensino consistia no Método Audiolingual.

Os participantes foram selecionados a partir dos seguintes critérios: (1) haver estudado inglês de forma consecutiva em um período de dois a três anos, sem interrupções, apresentando, portanto, um mesmo nível de escolaridade em inglês; (2) haver estudado inglês através de um único método, quer em uma mesma escola quer em várias; (3) serem monolíngües em português, sem nunca terem morado em país de língua inglesa ou de outra língua que não o português; (4) ser o inglês a primeira e a única língua estrangeira que aprenderam ou estavam aprendendo.

\section{Material}

Dois textos foram utilizados: uma história em português ${ }^{10}$ (Apêndice 1) e uma em inglês" (Apêndice 2). Os textos eram semelhantes quanto a diversos aspectos: (a) pertenciam a um mesmo gênero textual (narrativo literário); (b) versavam sobre personagem incomum; (c) apresentavam semelhanças quanto ao número e características dos personagens principais; (d) envolviam cenários do cotidiano; e (e) a conclusão requeria o estabelecimento de inferências essenciais para a compreensão do texto. Algumas adaptações foram feitas no sentido de tornar próximo o número de palavras das histórias (499,

\footnotetext{
"A história em português intitulada "História triste de tuim", foi escrita por Rubem Braga, retirada da coletânea "Para Gostar de Ler", volume I - Crônicas, Editora Ática, 1986.

"A história em inglês intitulava-se "The Manatee", escrita por Philippa Pearce, retirada da coletânea "Lion at School and Other Stories", Puffin Books, 1986.
} 
em português e 474, em inglês) e quanto à criação de passagens que envolvessem o estabelecimento de inferências.

\section{Procedimento e planejamento experimental}

A coleta foi realizada individualmente em duas sessões com um intervalo de dois dias entre elas. Duas tarefas de compreensão foram aplicadas: reprodução de uma história lida e responder perguntas sobre esta mesma história. Na primeira sessão, os participantes realizaram as tarefas de compreensão da história em português e na segunda sessão, realizaram as tarefas de compreensão da história em inglês. As instruções e a realização das tarefas ocorriam em português. Esclarecimentos sobre palavras desconhecidas eram fornecidos. Ambas as sessões foram gravadas e posteriormente transcritas o mais literalmente possível.

A Tarefa de Reprodução consistia na leitura de um texto pelo participante, sendo solicitado a reproduzir oralmente a história com suas próprias palavras. Esta tarefa avalia a compreensão de textos de maneira global, focalizando a capacidade do indivíduo em selecionar espontaneamente as informações relevantes de um dado texto, reproduzindo as relações essenciais entre elas. Avalia, ainda, a capacidade de reproduzir fielmente as informações contidas no texto original, respeitando sua sequiência e organização estrutural de forma a reproduzir um texto coerente e integrado.

A Tarefa de Perguntas consistia em responder a perguntas literais e inferenciais (Tabela 2) que eram apresentadas oralmente em uma ordem fixa, seguindo a sequiência em que as informações apareciam no texto. Esta tarefa avalia, ao contrário da reprodução, a compreensão pontual a respeito de determinadas informações e partes específicas do texto. Nesta tarefa, o participante não precisava selecionar as informações relevantes, como ocorre na reprodução, pois as perguntas já se encarregaram de fazer esta seleção por ele ${ }^{12}$. Através de perguntas é possível avaliar se determinadas informações relevantes que não foram espontaneamente mencionadas na reprodução da história foram ou não compreendidas

\footnotetext{
Para maiores detalhes a respeito das diferentes demandas linguísticas e cognitivas envolvidas em diferentes tarefas de compreensão de textos usualmente adotadas na pesquisa na área, consultar Brandão e Spinillo (1998).
} 
pelo indivíduo. Desta forma, ambas as tarefas de compreensão adotadas se complementam.

\begin{tabular}{|c|c|c|}
\hline \multicolumn{2}{|r|}{ Perguntas sobre o texto em Português } & Natureza \\
\hline 01 & Onde o menino achou o tuim? & Literal \\
\hline 02 & Que tipo de bicho é o tuim? Como você sabe? & Inferencial \\
\hline 03 & Quantos tuins havla na casa que o menino achou? & Literal \\
\hline 04 & O tuim do menino tinha partes azuis? & Inferencial \\
\hline 05 & Por que o menino vivia com o ouvido no ar? & Inferencial \\
\hline 06 & $\begin{array}{l}\text { Ao voltarem para São Paulo, o paj avisou ao } \\
\text { menino que o tuim não podia andar solto. Por que? }\end{array}$ & Literal \\
\hline 07 & Em São Paulo, onde ficava o tuim? & Literal \\
\hline 08 & $\begin{array}{l}\text { Pouco tempo depois, isto já em São Paulo, o tum } \\
\text { do menino sumiu. Que idéia teve o menino quando } \\
\text { não conseguiu achar o tuim? }\end{array}$ & Literal \\
\hline 09 & O que fez o menino com a tesoura? & Inferencial \\
\hline 10 & O que aconteceu com o tuim no final da história? & Inferencial \\
\hline \multicolumn{2}{|r|}{ Perguntas sobre o texto em I nglês } & Natureza \\
\hline 01 & $\begin{array}{l}\text { O que Totty e seu avô comeram após irem ao } \\
\text { parque? }\end{array}$ & Literal \\
\hline 02 & De que falava o livro que o seu avô Ihe mostrou? & Literal \\
\hline 03 & $\begin{array}{l}\text { Que tipo de animal é o manatee? Como você } \\
\text { sabe? }\end{array}$ & Inferencial \\
\hline 04 & Por que Totty ficou com medo do manatee? & Inferencial \\
\hline 05 & $\begin{array}{l}\text { Como eram os camas no Querto em que Totty } \\
\text { ficou? }\end{array}$ & Literal \\
\hline 06 & Que tipo de som, vindo da escada, Totty escutou? & Literal \\
\hline 07 & $\begin{array}{l}\text { Após ouvir o som, Totty fechou os olhos. O que } \\
\text { ele viu quando abriu os olhos? }\end{array}$ & Literal \\
\hline 08 & $\begin{array}{l}\text { Por que Totty ficou feliz em saber que manatee } \\
\text { eram vegetarianos? }\end{array}$ & Inferencial \\
\hline 09 & $\begin{array}{l}\text { Qual a idéia errônealerrada que o avô de Totty } \\
\text { tinha sobre os manatee? }\end{array}$ & Inferencial \\
\hline 10 & $\begin{array}{l}\text { Ern que Totty estava pensando quando sorriu no } \\
\text { final da história? }\end{array}$ & Inferencial \\
\hline
\end{tabular}

Tabela 2: Perguntas apresentadas. 
A ordem fixa de aplicação das tarefas deveu-se a duas razões: (a) optou-se pela reprodução antes das perguntas de maneira a evitar que as perguntas influenciassem a reprodução da história; e (b) optou-se por aplicar primeiro as tarefas em português porque os resultados de um estudo piloto mostraram que os participantes sentiam-se mais à vontade quando a primeira história era em português, sua língua materna, do que quando iniciava-se pela história em inglês.

\section{Análise dos dados Reprodução da história}

As reproduções foram analisadas com base nas categorias propostas por Brandão e Spinillo $(1998 ; 2001)^{13}$, e com base na presença ou ausência de duas inferências cruciais para a compreensão do texto em português (1. Que tipo de animal era o tuim; e 2. O que aconteceu ao tuim no final da história); e de duas inferências cruciais para a compreensão do texto em inglês (1. Que tipo de animal era o manatee; e 2. O manatee visitou o menino ou isso foi apenas um sonho). As categorias utilizadas são descritas e exemplificadas a seguir ${ }^{14}$ :

Categoria I - reproduções globais, com referência ao problema central e ao desfecho. Observa-se omissão e/ou troca de informações relevantes. Reproduções incompletas, principalmente quanto à cadeia causal da história. As duas inferências principais não são mencionadas.

Exemplo 1 (texto em inglês): "A história fala de... é... um menino foi visitar o avô e tava lendo um livro e viu um bicho assim imaginário. Aí perguntou pro avô onde ele vivia e o que ele comia. O avô disse que ele vivia na água; só disse isso. E... ele ficou assustado, mas não valeu a pena, porque o bicho não fazia mal a ninguém."

\footnotetext{
${ }^{3}$ Estas categorias tiveram origem em uma análise realizada por Marcuschi (1989) em que o texto original era dividido em blocos de informação. A reprodução era analisada em função da presença/ausência desses blocos.

${ }^{14}$ As reproduções exemplificadas são apresentadas o mais fielmente possivivel, justificando-se, assim, o uso de expressões coloquiais e pausas. Como os textos foram reproduzidos oralmente, o emprego da pontuação foi atribuído pelo examinador em suas transcrições.
} 
Exemplo 2 (texto em português): "O tuim... Tinha um menino que foi passar as férias numa granja. Nessa granja havia uma árvore, que nessa árvore tinha uma casa. Nela, quando o menino subiu, encontrou três tuins, quatro tuins: isso aí. Aí ele pegou o tuim, esses três tuins e levou para dentro de casa. Dois morreram e só ficou um. Com esse tuim, ele ficou o tempo todo com ele, todas as férias com ele. E, toda vez que aparecia visita na casa, o tuim começava a fazer brincadeira. E o pai dele vivia falando: "Toda vez que passar um bando de tuim, o tuim tem que ir embora, porque senão ele vai morrer de tristeza." Então, um dia passou um bando de tuim e o menino começou a chorar, chorar pensando que o tuim tinha ido embora. Mas, de repente, viu que o tuim estava na varanda. Ai todos ficaram muito felizes. $O$ menino, por sua teimosia, deixou o tuim um dia solto no quintal, pois toda vez que chamava, ele voltava. Mas teve uma vez que o tuim não voltou. Então, o menino procurou pelos vizinhos, o tuim, e não encontrou. Aí o menino foi no armazém de perto e perguntou se alguém tinh a comprado comida de tuim. Então, o menino pegou, foi na casa chorando e pegou o tuim de volta e voltou para casa e nunca mais deixou ele solto no quintal. Pronto!"

Categoria II - semelhante à Categoria I, porém as reproduções são completas, estando presente a cadeia causal da história. Apenas uma das duas inferências principais é explicitada.

Exemplo 3 (texto em português): "É a história de um menino que um dia subiu numa árvore bem alta... ai ele já tava perto lá do ninho de tuim, era uma casinha. Lá no quartinho escondido tinham três filhotinhos ; aî ele, com uma varinha de bambu, pegou, sem quebrar. Aî ele pegou e levou pra casa, ai um tuim morreu, depois outro morreu, ai ficou um. Já onde as pessoas criam tuim de casal, pra ver os dois namorando mas, como os dois morreram, ele foi criado sozinho. Aío pai do menino vivia dizendo que tuim era acostumado a viver em bandos e, se um dia aparecesse um bando, ele tinha que ir, porque se o menino não deixasse ele ir e, ele ficasse preso, ele podia morrer de tristeza. Aí um dia... assim...combinaram pra ver ser ia ou não ia levar ele pra cidade, porque eles tavam de férias; ai eles resolveram que iam levar. Aí, lá na cidade, ele não deixava o tuim sair porque ele podia fugir, mas ai ele achou que um dia se deixasse o tuim brincar no quintal um pouquinho não ia ter problema nenhum, aí ele deixou. Aí, todo dia ele deixava, aí 
ele fala "Vem cá, tuim, aí toda vez ele ia, aí teve uma vez que ele não veio, ai o filhote ficou todo preocupado, ai o tuim...ele saiu procurando de casa em casa, aí não achou; aí ele teve uma idéia, ele foi no armazém onde comprava comida de tuim e falou se alguém tinha comprado a comida... aí falaram que sim, aí ele foi chorando e caminhando pra casa de onde tinham comprado e lá, ele voltou com o tuim alegre. Ai, ele pegou uma tesoura e cortou a asinha do tuim e... pra ele não fugir mais... Aí, deixou, brincar no quintal."

Categoria III - reproduções completas, estando presente a cadeia causal da história. As duas principais inferências são explicitadas.

Exemplo 4 (texto em português): "É! Foi um menino que ele estava passando suas férias na roça. Entäo, um dia ele viu uma casinha em cima de um galho; então, ele subiu e não conseguiu chegar muito perto, e com uma vara de bambu tirou aquela casinha e, lá dentro, havia três passarinhos. Os passarinhos eram... (pausa) tuins! É... ele então pegou estes três passarinhos e começou a cuidar deles, um... eles eram muito feios, eles tinham um... quase não tinham rabo eram verde. Então, ele começou a cuidar dos tuins, e um dia os dois morreram e só ficou um. Então, ele levou para sua casa e começou a cuidar dele, então resolveu deixar ele na árvore. Todo dia quando ele chamava, o tuim aparecia. Mas seu pai sempre vinha avisando para ele que um dia, quando um bando de tuins passasse, ele ia junto. Então, um dia, quando ele estava catando minhocas para pescar, ouviu um bando passando e, quando chamou o tuim, o tuim não apareceu. Então, ele começou a chorar e seu pai... e ele só parou de chorar quando seu pai lhe deu uma bronca, dizendo que um dia isso poderia acontecer. Então, quando ele menos esperou, passou o tuim... e veio o tuim voando, então ele ficou muito alegre. Então teve uma reunião de família e eles voltaram para São Paulo e ele resolveu trazer o tuim pra casa. Ele começou a cuidar do tuim com muito amor... O pai dele disse que ele era um bicho da roça, que não podia ficar muito preso. Então, ele resolveu deixar o tuim no quintal de sua casa. É... ele estava brincando e quando chamou o tuim, o tuim não apareceu, então ele começou a chorar e saiu perguntando pela sua vizinhança se alguém tinha visto tuim. Ninguém encontrou. Até que ele teve a idéia de ir até o armazém, quando chegou lá, perguntou se alguém tinha comprado comida para tuim. E o homem disse que uma pessoa de uma casa havia comprado. Então ele foi lá e viu e trouxe o 
tuim todo alegre. E só havia um jeito de deixar o tuim no seu quintal sem fugir. Ele pegou uma tesoura e cortou suas asas. E quando ele foi lá dentro buscar comida para o tuim, quando voltou, chamou o tuim, o tuim não veio e viu umas marcas de sangue na calçada. E quando olhou assim para o lado, viu um felino ruivo com o tuim... é... que havia comido o tuim."

Como pode ser notado, essas categorias de reprodução, como afirmado por Marcuschi (1996), se constituem em um tipo de retextualização, uma vez que ao mesmo tempo que depende de um modelo fornecido previamente pelo texto original, o texto reproduzido sofre modificações que decorrem, no caso, de variações de compreensão do leitor.

As reproduções foram analisadas por dois juizes independentes, cujo índice de concordância entre eles foi de $73.5 \%$. Os casos de desacordo foram julgados por um terceiro juiz, também independente, cuja classificação foi considerada final. A Tarefa de Perguntas foi analisada em função do número de acertos.

\section{Resulltados}

\section{Reprodução da História}

Como ilustra a Tabela 3, o Qui-quadrado não detectou diferenças significativas entre as escolas quanto à reprodução do texto em português $\left(c^{2}=.20, p>.05\right)$, visto que a maioria das reproduções em toda a amostra se concentra na Categoria II (cadeia causal presente e uma das inferências é explicitada). Isto significa que os participantes em ambos os grupos apresentavam um mesmo nível de compreensão de textos em português.

No texto em inglês, entretanto, verificou-se diferenças significativas entre as escolas $\left(c^{2}=6.63, p<.05\right)$. Os alunos da Abordagem Comunicativa apresentavam um melhor desempenho em compreensão de textos em inglês do que os alunos do Método Audiolingual, visto que a quase totalidade das reproduções se concentrava na Categoria II e nenhuma delas alcançou a Categoria III (cadeia causal presente e as duas infer6encias são explicitadas); enquanto $26.7 \%$ das produções da Abordagem Comunicativa foram classificadas nesta categoria mais elaborada. 


\begin{tabular}{|c|c|c|c|c|}
\hline \multirow{2}{*}{ Categorias } & \multicolumn{2}{|c|}{ Comunicativa } & \multicolumn{2}{c|}{ Audiolingual } \\
\cline { 2 - 5 } & $\begin{array}{c}\text { Texto em } \\
\text { Português }\end{array}$ & $\begin{array}{c}\text { Texto em } \\
\text { Inglês }\end{array}$ & $\begin{array}{c}\text { Texto em } \\
\text { Português }\end{array}$ & $\begin{array}{c}\text { Texto em } \\
\text { Inglês }\end{array}$ \\
\hline I & $3(20)$ & $1(6.7)$ & $3(20)$ & $1(6.7)$ \\
\hline II & $8(53.3)$ & $10(66.6)$ & $9(60)$ & $14(93.3)$ \\
\hline III & $4(26.7)$ & $4(26.7)$ & $3(20)$ & 0 \\
\hline
\end{tabular}

Tabela 3: Frequiência e percentagem (em parênteses) de participantes em cada categoria na Tarefa de Reprodução.

Comparando-se o desempenho na compreensão de textos em inglês e em português em cada grupo de alunos, não se detectou diferenças significativas tanto em relação aos alunos da Abordagem Comunicativa como em relação aos alunos do Método Audiolingual (p>.05). No entanto, embora esta diferença não seja estatisticamente significativa, vale ressaltar que os alunos do Método Audiolingual tiveram um melhor desempenho com o texto em português (Categoria III: 20\%) do que com o texto em inglês (Categoria III: $0 \%$ ).

Outra diferença entre os dois grupos de alunos refere-se à compreensão do texto em inglês: os alunos da Abordagem Comunicativa apresentavam desempenho significativamente superior aos alunos do Método Audiolingual (Comunicativa: 26,7\% na Categoria III; e Audiolingual: $0 \%$ na Categoria III). Nota-se, portanto, que nenhum aluno do Método Audiolingual no texto em inglês explicitava as duas inferências cruciais, enquanto quatro dos alunos da Abordagem Comunicativa $(26,7 \%)$ o fizeram. Este resultado sugere que, embora todos os participantes tivessem um bom nível de compreensão de textos na língua materna, existiam níveis distintos de compreensão quanto a textos em língua inglesa, diferença esta que parece estar associada ao método de ensino ao qual o aluno foi submetido. Esta diferença favorece os alunos da Abordagem Comunicativa. As razões que justificam esta diferença são discutidas ao final deste artigo. 


\section{Perguntas sobre a História}

Como ilustra a Tabela 4, de modo geral, o percentual de acertos foi semelhante em ambas as escolas e em ambos os textos (português e inglês).

\begin{tabular}{|c|c|c|}
\hline \multirow{2}{*}{ Texto } & \multicolumn{2}{|c|}{ M étodo de Ensino } \\
\cline { 2 - 3 } & Comunicativa & Audiolingual \\
\hline Português & $120(80)$ & $122(81.3)$ \\
\hline Inglês & $116(77.3)$ & $106(70.7)$ \\
\hline
\end{tabular}

Tabela 4: Freqüência e percentagem (em parênteses) de acertos em cada texto e em cada método de ensino

Entretanto, este padrão geral de resultados não é observado ao se considerar o desempenho nas perguntas literais e nas perguntas inferenciais separadamente (Tabela 5).

\begin{tabular}{|c|c|c|c|c|}
\hline \multirow{2}{*}{$\begin{array}{c}\text { Método } \\
\text { de ensino }\end{array}$} & \multicolumn{2}{|c|}{ Português } & \multicolumn{2}{c|}{ Inglês } \\
\cline { 2 - 5 } & Inferenciai & Literal & Inferencial & Literal \\
\hline Comunicativa & $57(76)$ & $63(84)$ & $56(74.7)$ & $60(80)$ \\
\hline Audiolingual & $59(78.7)$ & $63(84)$ & $44(58.7)$ & $62(82.7)$ \\
\hline
\end{tabular}

Tabela 5: Freqüência e percentagem (em parênteses) de acertos em cada tipo de pergunta em funçāo da língua em que o texto foi apresentado e do mélodo de ensino.

Entre os alunos da Abordagem Comunicativa, como indicado pelo Teste Wilcoxon, não foram encontradas diferenças significativas no número de acertos entre perguntas inferenciais e literais, tanto no texto em português $(\mathrm{Z}=-1.18, \mathrm{p}>0.05)$ como no texto em inglês $(\mathrm{Z}=-1.27$, $\mathrm{p}>0.05$ ).

Entre os alunos do Método Audiolingual, diferenças significativas entre as perguntas foram encontradas apenas em relação ao texto em inglês $(\mathrm{Z}=2.71, \mathrm{p}<=.01)$, visto que o desempenho foi melhor nas perguntas literais $(82.7 \%$ ) do que nas perguntas inferenciais $(58.7 \%)$.

Assim, enquanto para os alunos da Abordagem Comunicativa as perguntas inferenciais e literais eram corretamente respondidas, tanto em inglês como em português; para os alunos do Método Audiolingual 
as perguntas inferenciais eram mais difíceis do que as literais no texto em inglês. Ao que parece, as perguntas inferenciais em inglês foram uma dificuldade para os alunos do Método Audiolingual, mas não para os alunos da Abordagem Comunicativa.

Comparações entre as duas abordagens, em relação a cada língua separadamente, foram feitas através do Teste U de Mann-Whitney. Considerando o desempenho apenas em relação ao texto em português, não foram verificadas diferenças significativas entre os alunos dos dois métodos em relação ao número de acertos às perguntas inferenciais $(\mathrm{U}=93.0, \mathrm{p}>.05)$ e nem em relação às literais $(\mathrm{U}=92.5, \mathrm{p}>.05)$. Considerando o desempenho apenas em relação ao texto em inglês, também não se observou diferenças entre os alunos dos dois métodos quanto ao número de acerto nas perguntas literais $(U=105.0, p>.05)$. Na realidade, a única diferença encontrada entre os grupos foi que, em inglês, os alunos da Abordagem Comunicativa apresentavam um maior número de acertos nas perguntas inferenciais do que os alunos do Método Audiolingual $(\mathrm{U}=68.5, \mathrm{p}=.05)$.

Em função dos resultados obtidos, verifica-se que os alunos do Método Audiolingual se assemelham em compreensão de textos em português aos alunos da Abordagem Comunicativa. No entanto, quando se considera a compreensão de textos em inglês, os alunos do Método Audiolingual apresentam níveis de compreensão de texto mais elementares do que os da Abordagem Comunicativa. Isto foi observado tanto na Tarefa de Reprodução como na Tarefa de Perguntas. Os alunos do Método Audiolingual reproduziam histórias incompletas, estando ausente uma das inferências relevantes ou ambas; enquanto os alunos da Abordagem Comunicativa tendiam a fazer reproduções completas, estando explicitadas as duas inferências cruciais à compreensão do tex to em inglês, ou pelo menos, uma delas.

$\mathrm{Na}$ Tarefa de Perguntas, os alunos do Método Audiolingual tiveram dificuldades com as perguntas inferenciais no texto em inglês, o mesmo não ocorrendo com os alunos as Abordagem Comunicativa. As razões para este resultado são discutidas a seguir.

\section{Conclusões e discussão}

A principal conclusão deste estudo é que o método adotado para o ensino de inglês como língua estrangeira influencia a compreensão de 
textos em inglês, seja em tarefas de reprodução de textos seja em respostas a perguntas sobre o texto. Este efeito foi observado mesmo entre leitores que apresentavam um bom nível de compreensão de textos em sua língua materna (português). Considerando que a compreensão de textos é um processo inferencial que requer a construção e integração de significados a partir das informações contidas no texto e do conhecimento de mundo do leitor (Kintsch, 1998; Marcuschi, 1984; 1996; Yuill e Oakhill, 1991), verificou-se que os alunos do método baseado na comunicação lidavam com tais aspectos de forma mais efetiva do que os alunos do Método Audiolingual, os quais não reproduziam todas as informações inferenciais cruciais para a compreensão do texto e apresentavam erros nas perguntas inferenciais. A compreensão de textos parece ser favorecida por situações de aprendizagem nas quais a língua é tratada como um sistema de comunicação que objetiva a busca de significados, mais do que por situações de aprendizagem que concebem a língua como um código a ser decifrado.

Assim, diferentes métodos de ensino de língua estrangeira geram diferenças na habilidade de compreensão de textos na língua em questão. O Método Audiolingual, em função da concepção de língua que adota, concebe e utiliza o texto como um instrumento de treino de leitura; enquanto a Abordagem Comunicativa considera o texto um instrumento que veicula um sentido a ser compreendido, estimulando a capacidade de selecionar informações relevantes em um dado texto e o estabelecimento de inferências. Importante mencionar que estudos que compararam diferentes métodos de ensino da língua materna nas práticas de alfabetização de crianças mostraram resultados semelhantes: crianças alfabetizadas através de abordagens comunicativas apresenta níveis de compreensão de textos mais elaborados do que crianças alfabetizadas por métodos que enfatizavam a decodificação, o vocabulário, a ortografia e o ensino da gramática (e.g., Archanjo, 1998; Buarque e Rego, 1994; Nunes, 1995).

Como mencionado, há uma escassez de pesquisas que se proponham a comparar os ganhos linguísticos derivados de métodos distintos no ensino de uma língua estrangeira. Além da compreensão de textos, seria interessante examinar que outras habilidades linguísticas poderiam ser influenciadas pelo método de ensino de língua estrangeira. Por exemplo, comparar as habilidades de produção escrita de textos em inglês em alunos submetidos a uma Método Audiolingual e em alunos submetidos 
a uma Abordagem Comunicativa. Diversos aspectos poderiam ser tomados para análise: o uso de recursos coesivos, a coerência textual ou o domínio da estrutura textual.

Estudos de intervenção também poderiam ser conduzidos, como por exemplo, programas instrucionais que tratassem de forma sistemática o uso de estratégias que facilitassern a integração das informações e o estabelecimento de inferências, aspectos esses essenciais à compreensão de textos. Em investigação sobre atividades que desenvolvem a compreensão, Brown, Palincsar e Armbruster (1994) afirmam que da mesma forma que a decodificação é exaustivamente ensinada nas escolas, a compreensão de textos deveria ser tratada de forma semelhante. Estratégias de compreensão de textos deveriam ser ensinadas de maneira formal, explícita e regular, criando-se oportunidades para: (a) uma avaliação crítica do conteúdo do texto; (b) monitoramento da leitura e estratégias para garantir que a compreensão está sendo alcançada; e (c) explicitação dos vários tipos de inferências, predições e conclusões sobre o texto.

Enquanto o presente estudo comparou o efeito de dois métodos de ensino já existentes sobre a compreensão de textos em inglês, pesquisas futuras poderiam avaliar o efeito de um programa de intervenção especificamente voltado para a compreensão de textos, como sugerido por Brown, Palincsar e Armbruster (1994); comparando-se um grupo controle e outro experimental, realizando-se pré-testes e pós-testes antes e após a intervenção. Estudos desta natureza e com um planejamento experimental deste tipo poderiam contribuir para a implementação de práticas mais eficazes de ensino de uma língua estrangeira.

\section{Referências bibliográficas}

ARCHANJO, R.V.L. Diferenças nas abordagens de ensino afetam a leitura e compreensão de textos narrativos?. 1998. 149 f. Dissertação (Mestrado em Psicologia) - Pós-Graduação em Psicologia, Universidade Federal de Pernambuco, Recife.

BRANDÃO, A.C.P.; SPINILLO, A.G. Aspectos gerais e específicos na compreensão de textos. Psicologia: Reflexão e Crítica, Porto Alegre, v.11, n. 2, p.253-272, 1998. 
BRANDÃO, A.C.P.; SPINILLO, A.G. Produção e compreensão de textos em uma perspectiva de desenvolvimento. Estudos em Psicologia, Natal, v.6, n.1, 51-62, 2001.

BROWN, A.L.; PALINCSAR, A.S.; ARMBRUSTER, B.B. Instructing comprehension-fostering activities in interactive learning situations. In: RUDDELL, R.B.; RUDDELL, M.R.; SINGER, H. (Ed.), Theoretical models and processes of reading. Delaware: International Reading Association, 1994, p.757-787.

BUARQUE, L.L.; REGO, L.L.B. Alfabetização e construtivismo: teoria e prática. Recife: Editora Universitária da UFPE, 1994. 118p.

CAMPBELL, M.C. Guided design: critical thinking and proficiency in the university foreign language classroom. In: TOPPING, D.M.; CROWELL, D.C.; KOBAYASHI, V.N. (Ed.). Thinking across cultures. Hillsdale, NJ.: Lawrence Earlbaum Associates, 1989. p. 445-453.

CANALE, M.; SWAIN, M. Theoretical bases of communicative approaches to second language teaching and testing. Applied Linguistics, v.1, n.1, p.1-47, 1980.

COHEN, A.D. Strategies in learning and using a second language. New York: Addison Wesley Longman, 1998.

FINOCCHIARO, M.; BRUMFIT, C. The functional-notional approach: from theory to practice. New York: Cambridge University Press, 1983. GRAESSER, A.C.; BRITTON, B.K. Five metaphors for text understanding. In: BRITTON, B.K.; GRAESSER, A.C. (Ed.). Models of understanding text. Mahwah, N.J.: Lawrence Earlbaum Associates, 1996. p. 341-352.

GRAESSER, A.C.; SINGER, M.; TRABASSO, T. Constructing inferences during narrative text xomprehension. Psychological Review, v.101, n.3, p. 271-395, 1994.

GRAESSER, A.C; SWAMER, S.; BAGGETT, W.B.; SELL, M.A.. New models of deep comprehension. In: BRITTON, B.K.; GRAESSER, A.C. (Ed.). Models of understanding text. Mahwah, N.J.: Lawrence Earlbaum Associates, 1996. p. 1-32.

GRAESSER, A.C; ZWAAM, R. A. Inference generation and the construction of situation models. In: WEAVER III, C.A.; MANNES, S.; FLETCHER, C.R. (Ed.). Discourse comprehension: essays in honor of 
Walter Kintsch. Hillsdale, NJ.: Lawrence Earlbaum Associates, 1995. p. 117-140.

KINTSCH, W. The use of knowledge in discourse processing: a construction-integration model. Psychological Review, v. 95, p. 163-182, 1988.

KINTSCH, W. Comprehension. A paradigm for cognition. Cambridge: Cambridge University Press, 1998. 461p.

KINTSCH, W.; VAN DIJK, T.A. Towards a model of text comprehension and production. Psychological Review, v. 85, p. 363-394, 1978.

LITTLEWOOD, W. Communicative language teaching. Cambridge: Cambridge University Press, 1981.

LITTLEWOOD, W. Foreign and second language learning: language acquisition research and its implications for the classroom. Cambridge: Cambridge University Press, 1984.

MARCUSCHI, L.A. O processo inferencial na compreensão de textos. Relatório técnico de projeto de pesquisa, CNPq, Brasília, 1989.

MARCUSCHI, L.A. Exercícios de compreensão ou copiação nos manuais de ensino de língua? Em Aberto, Brasília, v.16, n. 69, p.63-82, 1996.

NUNES, S.R. Comparando habilidades de leitura e escrita em crianças, alfabetizadas por diferentes metodologias. $130 \mathrm{f}$. Dissertação (Mestrado em Psicologia) - Departamento de Psicologia, Universidade Federal de Pernambuco, Recife, 1995.

OAKHILL, J.; YUILL, N. Higher order factors in comprehension disability: Process and remediation. In: CORNOLDI, C.; OAKHILL, J. (Ed.), Reading comprehension difficulties: process and intervention. Hillsdale, NJ.: Lawrence Erlbaum Associates, 1996. p. 69-92.

PERFETTI, C.A.; MARRON, M.A.; FOLTZ, P.W. Sources of comprehension failure: theoretical perspectives and case studies. In: CORNOLDI, C.; OAKHILL, J. (Ed.), Reading comprehension difficulties: process and intervention (pp. 137-165). Hillsdale, NJ.: Lawrence Erlbaum Associates, 1996. p. 137-165.

PINTO, A.P.P. Processos cognitivos e estilos individuais: uma proposta para o desenvolvimento da autonomia do leitor. 1996. Tese (Doutorado em Linguiística) -Faculdade de Letras, Pontifícia Universidade Católica de São Paulo, São Paulo. 1996. 
RICHARDS, J.C.; RODGERS, T.S. Approaches and methods in language teaching. Cambridge: Cambridge University Press, 1986.

UPTON, T.A. First and second language use in reading comprehension strategies of Japanese ESL students. TESL-EJ, 3 (1A-3), p.1-27, 1997. VAN DIJK, T.A.; KINTSCH, W. Strategies of discourse comprehension. New York: Academic Press, 1983. 226p.

YUILL, N.; OAKHILL, J. Children's problems in text comprehension: an experimental investigation. Cambridge: Cambridge University Press, 1991. 241p.

\section{Apêndice 1: Texto em português}

A casa estava num galho alto, mas um menino subiu até perto, depois com uma vara de bambu conseguiu tirar a casa sem quebrar. Dentro, naquele quartinho que fica bem escondido depois do corredor de entrada para o vento não incomodar, havia três filhotes de tuim.

Tuim tem rabo curto e é todo verde, mas o macho tem umas partes azuis para enfeitar. Eram três filhotes, um mais feio que o outro, os três chorando. O menino levou-os para casa, inventou comidinha para eles; um morreu, outro morreu, ficou um.

Geralmente se cria em casa é casal de tuim, para se apreciar o namorinho deles. Mas aquele tuim macho foi criado sozinho. Passava o dia todo comendo sementinhas de imbaúba. Se aparecia uma visita, faziase aquela demonstração: era o menino chegar na varanda e gritar para o arvoredo: tuim, tuim, tuim! Às vezes demorava, então a visita achava que aquilo era brincadeira do menino, de repente surgia o tuim.

Mas o pai avisava sempre ao menino que tuim é acostumado a viver em bando. No dia que passasse um bando, adeus tuim. E ainda completava dizendo que se o tuim não fosse com o bando, ele era capaz de morrer de tristeza.

O menino vivia de ouvido no ar.

Foi um dia de manhã, o menino estava catando minhoca para pescar quando ouviu um bando chegar. O menino correu e correu mas não conseguiu chegar a tempo. E nada de tuim. Só parou de chorar quando o pai chegou e brigou com ele, dizendo que estava avisado de que aquilo podia acontecer. 
O menino parou de chorar, porque tinha brio, mas como doía seu coração! De repente, olhe o tuim na varanda! Foi uma alegria na casa.

Houve quase um conselho de família, quando acabaram as férias: deixar o tuim, levar o tuim para São Paulo? Voltaram para a cidade com o tuim. O pai avisou que ele não podia andar solto pois era bicho da roça.

Dito e feito. A princípio o menino fechava as janelas. A mãe e a irmã não aprovavam. O menino então achou que soltar o tuim no quintal; só um pouquinho não devia ser perigoso. E assim foi. Era só o menino chamar, que o tuim voltava. Mas uma vez não voltou.

De casa em casa, o menino foi indagando pelo tuim, e as pessoas perguntavam o que era tuim. Nada de tuim.

Até que teve uma idéia. Foi ao armazém e perguntou se alguém havia comprado comida para tuim. Sim, tinham vendido para uma casa ali perto. Foi lá chorando e voltou para casa alegre com o tuim.

Pegou uma tesoura: era triste, era uma judiação, mas era preciso. Assim o bicho poderia andar solto no quintal, e nunca mais fugiria.

Depois foi lá dentro de casa pegar comida para o tuim. Quando voltou, viu só algumas manchas de sangue no cimento. Subiu num caixote para olhar por cima do muro, e ainda viu o vulto ruivo de um felino que sumia.

\section{Apêndlice 2: Texto em inglês}

Last weekend Totty went to visit his grandfather. It was the first time that Totty slept away from home.

During the visit, Totty and his grandfather went to the park together. Then they came back home. They had tea with baked beans and ice cream.

After tea, Totty's grandfather got out a book of wild animals pictures to show him. Totty's favorite animals were lions, tigers, jaguars and wolves. At the end of the book there was a picture of two dark gray creatures in the water of a strange river. They had big heads and tiny eyes and huge mouths. Totty could not see the animals' legs. He thought they were fish. But his grandfather told him that they were not fish. They were called manatees.

Totty was a bit scared and asked what food manatees ate. But his grandfather did not hear him. He was a very old man. He closed the book and told Totty to go to bed. 
Em the bedroom there were two beds. Totty chose the bigger bed. His grandfather said goodnight to him and turned off the bedroom light.

Totty did not go to sleep. He did not like the empty bed next to him. There was no light from the corridor. Everything was dark. Totty could not see anything. Then he heard a tiny, soft sound coming from the stairs.

There was nobody else in the house. His grandfather was in his bedroom. But there was something outside the bedroom. It was climbing up the stairs. Totty closed his eyes. Then opened his eyes quickly. It was a manatee.

Totty tried to open his mouth but it did not open. He tried to call his grandfather but he could not. The manatee was there. He was going to eat Totty. There was no way he could escape.

Totty had an idea! Luckily, there was some ice cream left in the refrigerator. Totty thought he could give the manatee some ice cream. So the manatee was not going to eat him!

The manatee looked at Totty. The manatee paid attention to Totty's face. Then, after some time, the manatee climbed into Totty's bed. Totty nearly fainted.

Slowly, very slowly the manatee moved from Totty's bed to the other bed. Totty thought he had heard the manatee saying 'Ha! How beautifully comfortable!'. Totty could not believe that! Totty waited a little bit. Then he went to sleep, too.

The next morning Totty looked at the bed but the manatee was not there. Totty went downstairs to have breakfast with his grandfather and asked him about the manatees. His grandfather told him they were very slow in their movements and that they were not dangerous. The manatees were vegetarians. Totty was happy. His grandfather also told him the manatees lived in the water and that they never came into houses. Totty smiled. 